\title{
PENGARUH IKLIM KOMUNIKASI DENGAN KINERJA PEGAWAI DI KANTOR KEMENTERIAN AGAMA KOTA BANJARMASIN
}

\author{
Muhammad Agus Humaidi \\ E-mail: m.agus.humaidi@gmail.com
}

FISIP Universitas Islam Kalimantan MAB Banjarmasin

\begin{abstract}
This study aims to determine the communication climate and employee performance in the Office of the Ministry of Religious Affairs of Banjarmasin, in addition to know the influence between the communication climate with the performance of employees in the Office of the Ministry of Religious Affairs Banjarmasin. The method used is a quantitative research approach and a research instrument with a questionnaire that is analyzed with Chi Square Goodness Of Fit and Simple Linear Regression.

The results showed that the communication climate of employees in the Office of the Ministry of Religious Affairs of Banjarmasin is quite good. While the performance of employees in the Office of the Ministry of Religious Affairs of Banjarmasin including less good category. In addition there is no influence between the communication climate on the performance of employees in the Office of the Ministry of Religious City of Banjarmasin.
\end{abstract}

Keywords: Communication Climate, Employee Performance 


\section{PENDAHULUAN}

Sumber daya manusia merupakan salah satu sumber daya yang terdapat dalam organisasi, meliputi semua orang yang melakukan aktivitas.Sumber daya yang terdapat dalam suatu organisasi bisa dikelompokan atas dua macam yaitu sumber daya manusia (human resource) dan sumber daya non manusia (non-human resource).Kelompok sumber daya non manusia ini mencakup modal, mesin, teknologi, bahan-bahan (material) dan lain-lain (Gomes dalam Hamali, 2016:2).

Dalam sebuah organisasi hal yang penting untuk diperhatikan adalah bagaimana menciptakan sebuah iklim komunikasi yang kondusif. Pace dan Faules (2001: 146), mengemukakan bahwa Iklim komunikasi dalam sebuah organisasi merupakan gabungan dari persepsi-persepsi mengenai peristiwa komunikasi, perilaku manusia, respon pegawai terhadap pegawai lainnya, harapan-harapan, konflik antar personal, dan kesempatan bagi pertumbuhan dalam organisasi tersebut.Pace dan Faules (2001: 152), menyatakan bahwa alasan lain yang mendukung pentingnya iklim komunikasi organisasi adalah karena dengan adanya iklim komunikasi organisasi yang kondusif, nyaman dan positif, maka dipercaya akan meningkatkan hasil kerja dari para anggota organisasi atau pegawai tersebut.

Hasil kerja secara kualitas dan kuantitas yang dicapai oleh seseorang anggota dalam melaksanakan tugasnya sesuai dengan tanggung jawab yang diberikan padanya merupakan arti dari kinerja (Mangkunegara dalam Widodo, 2015:131). Kinerja pegawai sangatlah perlu, sebab dengan kinerja ini akan diketahui seberapa jauh kemampuan mereka dalam melaksanakan tugas yang dibebankan padanya. Seruan bekerja dapat diketahui dari firman Allah SWT dalam surat At-Taubah ayat 105 (Depertemen Agama Republik Indonesia, Hal: 298) terjemahan adalah: Dan Katakanlah: "Bekerjalah kamu, Maka Allah dan rasul-Nya serta orang-orang mukmin akan melihat pekerjaanmu itu, dan kamu akan dikembalikan kepada (Allah) yang mengetahui akan yang ghaib dan yang nyata, lalu diberitakan-Nya kepada kamu apa yang Telah kamu kerjakan.

Tampaknya iklim komunikasi tehadap kinerja memiliki pengaruh, hal ini terbukti dari penelitian Yazid Halim (2016), yang menemukan hasil Ho ditolak dan Ha diterima atau iklim komunikasi organisasi berpengaruh terhadap kinerja karyawan di Rumah Sakit Umum Pusat (RSUP) Fatmawati. Selain itu dari penelitian Apriyanto Jurnal Komunikasi Bisnis dan Manajemen

Vol.6 No.1 Januari 2019 
Achmad Wibowo (2013), hasil penelitian ini menunjukkan bahwa Iklim komunikasi organisasi berpengaruh positif dan signifikan terhadap kinerja guru SMK Negeri 11 Semarang.Serta penelitian Nurul Andriana (2012), menunjukan hasil bahwa adanya pengaruh iklim komunikasi terhadap kinerja jurnalis TVRI yang signifikan.

Kantor Kementerian Agama merupakan salah satu pelaksana pemerintahan dibidang keagamaan dengan fungsi Merumuskan Visi dan Misi serta kebijakan tekhnis di bidang pelayanan dan bimbingan kehidupan beragama di Kota Banjarmasin. Melakukan pembinaan pelayanan dan bimbingan di bidang bimbingan masyarakat Islam, pelayanan haji dan umrah, pengembangan zakat dan wakaf, pendidikan agama dan keagamaan, pondok pesantren, pendidikan agama Islam pada masyarakat dan pemberdayaan masjid, urusan agama, pendidikan agama, bimbingan masyarakat Kristen, Katolik, Hindu serta Buddha sesuai peraturan perundang-undangan yang berlaku.Pelaksanaan kebijakan tekhnis di bidang pengelolaan administrasi dan informasi keagamaan, Pelayanan dan bimbingan di bidang kerukunan umat beragama, Pengkoordinasian perencanaan, pengendalian dan pengawasan program dan Pelaksanaan hubungan dengan pemerintah daerah, instansi terkait, serta lembaga masyarakat dalam rangka pelaksanaan tugas Departemen Agama di Kota Banjarmasin.

Peneliti tertarik untuk melakukan penelitian "Pengaruh iklim komunikasi terhadap kinerja pegawai di Kantor Kementerian Agama Kota Banjarmasin", karena selama observasi dalam melakukan penelitian di Kantor Kementerian Agama Kota Banjarmasin peneliti menemukan bahwa hubungan antara pegawai kurang harmonis, misalnya masih kurangnya komunikasi yang efektif antara beberapa pegawai hal ini dapat terlihat dalam pemberian tugas yang diberikan atasan, pegawai lamatidak berperan aktif dalam hal ini untuk memberikan masukan kepadapegawai yang sifatnya masih baru.Selain itu keramahan serta keakraban hanya terjadi pada sesama klik atau groupnya saja.Perbedaan persepsi antara sesama pegawai dengan adanya selentingan seperti pegawai satu merasa tidak disukai dengan rekannya dan pegawai merasa diabaikan dengan pimpinannya atau kepala bagiannya.

Peneliti juga melihat masih adanya pegawai yang mempunyai kinerja yang kurang optimal dalam melaksanakan tugas.Fenomena ini dapat dilihat dari pemberian peayanan kepada masyarakat yang kurang ramah, selain itu juga masih ada pegawai 
yang tidak melakukan pekerjaan tepat waktu setelah jam istirahat selesai.Dari permasalahan-permasalahan tersebut dapat diasumsikan, bahwa kemungkinan masalah kinerja yang terjadi di Kantor Kementerian Agama Kota Banjarmasin dipengaruhi iklim komunikasi yang kurang baik. Apabila tidak ditangani atau diabaikan begitu saja, maka akan merugikan pelayanan kepada mayarakat.

\section{TINJAUAN PUSTAKA}

\section{Iklim Komunikasi}

Face dan Faules menyatakan bahwa, "iklim komunikasi merupakan gabungangabungan dari persepsi-persepsi peristiwa komunikasi, perilaku manusia, respon pegawai terhadap pegawai lainnya, harapan-harapan, konflik-konflik antarpersona, dan kesempatan bagi pertumbuhan dalam organisasi tersebut". Lebih lanjut Redding menyatakan bahwa "iklim komunikasi organisasi jauh lebih penting dari pada keterampilan atau teknik-teknik komunikasi semata-mata dalam menciptakan suatu organisasi yang efektif" (Pace \& Faules, 2005:147).Dengan mengetahui sesuatu mengenai iklim suatu organisasi, akan dapat memahami dengan lebih baik apa yang mendorong anggota organisasi untuk bersikap dengan cara-cara tertentu.

Menurut Gibb iklim komunikasi tebagi menjadi 2 (dua) model, yaitu Supportive dan Defensive. Ada pun karakteristik dari masing-masing model yaitu: 1) Iklim Supportivedan 2) Iklim Defensive.Perkembangan iklim komunikasi dalam suatu organisasi dapat diidentifikasi darikomponen-komponen yang berperan serta dalam iklim tersebut, komponen yang dimaksudkandisini adalah unsur-unsur dasar organisasi seperti yang dikemukakan oleh Pace \& Faules (2005:150) yang menyatakan bahwaIklim komunikasi terkait dengan proses interaksi antara unsur-unsur dasar yang ada di dalam organisasi, seperti: pemimpin, karyawan lain, pekerjaan, struktur, dan pedoman dengan persepsi individu (anggota organisasi). Proses interaksi tersebut yang kemudian berpengaruh pada pola komunikasi dan pola interaksi anggota organisasi yang satu dengan yang lainnya.

Proses terbentuknya iklim komunikasi organisasi dan mengidentifikasi komponen-komponen yang berperan serta dalam iklim tersebut. Komponen-komponen diantaranya adalah unsur-unsur yang terdapat dalam organisasi, unsur-unsur tersebut 
tidak secara langsung membentuk iklim komunikasi, tetapi semuanya bergantung kepada persepsi anggota organisasi. Iklim komunikasi organisasi dapat memberikan gambaran kepada anggota organisasi mengenai seberapa jauh organisasi memberikan kepercayaan, mendukung anggota, menyediakan informasi yang cukup, terbuka, mendengarkan dengan penuh perhatian, melibatkan peran serta semua anggota, serta memperlihatkan perhatian lembaga atau organisasi terhadap anggota yang memiliki kinerja kerja yang tinggi.

Penelitian ini digunakan pendapat Pace dan Faules untuk mengukur baik tidaknya iklim komunikasi pegawai di Kantor Kementerian Agama Kota Banjarmasin, antara lain : 1) Kepercayaan; 2) Pembuatan keputusan bersama; 3) Kejujuran; 4) Keterbukaan dalam komunikasi kebawah; 5) Mendengarkan dalam komunikasi keatas dan 6) Perhatian pada tujuan-tujuan berkinerja tinggi.

\section{Kinerja}

Kinerjapegawai didefinisikan sebagai kemampuan pegawai dalam melakukan suatukeahlian tertentu. Kinerja pegawai sangatlah perlu, sebab dengan kinerja iniakan diketahui seberapa jauh kemampuan mereka dalam melaksanakan tugasyang diembankan kepadanya (Sinambela, 2016:480).Menurut Mangkunegara dalam Widodo (2015:131) bahwa istilah kinerja dari kata job performance atau actualperformance (prestasi kerja atau prestasi sesungguhnya yang dicapai olehseseorang) yaitu hasil kerja secara kualitas dan kuantitas yang dicapai olehseseorang pegawai dalam melaksanakan tugasnya sesuai dengan tanggungjawab yang diberikan padanya.

Manfaat penilaian kinerja antara lain : a) penilaian kinerja yang dilakukan dengan hati-hati dapat membantu memperbaiki kinerja pekerja sepanjang tahun, $b$ ) proses penilaian yang efektif merupakan bagian dari manajemen sumberdaya manusia yang dapat membantu organisasi berhasi, dan c) merupakan komponen kunci dari strategi kompetitif (Allen, 2007:43).Menurut Kirkpatrick (2006:68) mengatakan bahwa rencana perbaikan kinerja dirancang untuk mengubah perilaku pekerja. Untuk melakukan perubahan perilaku, perlu memenuhi lima persyaratan, sebagai berikut : 1) Desire (Keinginan); 2) Knowledge and skill (Pengetahuan dan Keterampilan); 3) Climate (Iklim); 4) Help and Support (Bantuan dan Dukungan); 5) Rewards (Penghargaan). 
Penelitian ini digunakan pendapat Bernardin \& Russel untuk mengukur kinerja pegawai di Kantor Kementerian Agama Kota Banjarmasin, antara lain : 1) Quality(Kualitas kerja), 2) Quantity (Kuantitas kerja), 3) Timeliness(Ketepatan waktu), 4) Cost efectiveness(Efektivitas biaya),5) Need for supervisior(Perlu untuk pengawasan), 6) Interpersonal impact.

\section{Pengaruh Iklim komunikasi terhadap Kinerja}

Salah satu data pendukung yang menurut peneliti perlu dijadikan bagian tersendiri adalah penelitian terdahulu yang relevandengan permasalahan yang sedang dibahas dalam penelitian ini.Dalam hal ini, fokus penelitian terdahulu yang dijadikan acuan adalah terkait dengan pengaruh iklim komunikasi terhadap kinerja.Oleh karena itu, peneliti melakukan langkah kajian terhadap beberapa hasil penelitian berupa jurnaljurnal melalui internet.Berdasarkan hasil-hasil penelitian yang telah dilakukan menyiratkan bahwa variabel iklim komunikasi memiliki pengaruh terhadap kinerja seperti hasil penelitian sebagai berikut :

Yazid Halim (2016) meneliti tentang pengaruh iklim komunikasi dalam organisasiterhadap kinerja karyawan di Rumah Sakit Umum Pusat (RSUP) Fatmawati, Hasil pengujian model regresi untuk keseluruhan variabel menunjukkan nilai F hitung $=352,164$ dengan signifikansi 0,000. Dengan menggunakan batas signifikansi 0,05, maka signifikansi 0,000<0,05. Ho ditolak dan Ha diterima.Selain itu penelitian dari Ahmad Fauzi (2014)tentang pengaruh iklim komunikasi organisasi terhadap kinerja aparatur di Pemerintahan Desa. Berdasarkan hasil uji analisis regresi statistik, nilai alpha $<0.05$ yang menunjukkan bahwaiklim komunikasi organisasi berpengaruh 33.8 persen terhadap kinerja aparatur dan praktik peneraan tatakelola yang baik berpengaruh 16.9 persen terhadap kinerja aparatur. Serta penelitian Apriyanto Achmad Wibowo (2013) tentangpengaruh iklim komunikasi organisasi dan budaya kerja terhadap kinerja guru SMK Negeri 11 Semarang juga menunjukan bahwa Iklim komunikasi organisasi berpengaruh positif dan signifikan terhadap kinerja guru SMK Negeri 11 Semarang, terbukti dari hasil analisis regresi dengan thitung $=12,431$ dan $p=0,000<0,05$.

Uraian di atas secara implisit menunjukkan bahwa iklim komunikasi organiasi berpengaruh positif terhadap kinerja pegawai. Hal ini menunjukkan bahwa makin baik 
iklim komunikasi, maka kinerja pegawaiakan makin meningkat juga. Sebaliknya, makin buruk iklim komunikasi, maka kinerja pegawai pun makin rendah pula.

\section{Kerangka Berfikir}

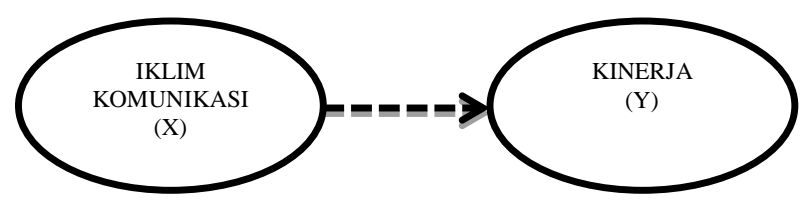

\section{Gambar 2.2. Kerangka Pemikiran Penelitian}

Iklim Komunikasi (X) sebagai variabel independen (variabel bebas) mempengaruhi variabel dependen (variabel terikat) Kinerja (Y).

\section{Hipotesis}

\section{Pengaruh Iklim Komunikasi terhadap Kinerja}

Ho: Tidak terdapat pengaruh antara Iklim Komunikasi tehadap Kinerja di Kantor Kementerian Agama Kota Banjarmasin.

$\mathrm{H}_{1}$ : Terdapat pengaruh antara Iklim Komunikasi tehadap Kinerja di Kantor Kementerian Agama Kota Banjarmasin.

\section{METODE PENELITIAN}

Dalam melakukan penelitian ini penulis memilih jenis penelitian kuantitatif, penelitian ini menggunakan metode penelitian deskriptif dan assosiatif.

Penelitian ini dilakukan di Kantor Kementerian Agama Kota Banjarmasin dengan objek mencakup Pengaruh iklim komunikasi terhadap kinerja pegawai di Kantor Kementerian Agama Kota Banjarmasin.

Populasi dalam penelitian ini adalah seluruh pegawai di Kantor Kementerian Agama Kota Banjarmasin yang berjumlah 107 orang. Dalam penelitian ini hanya sebagian populasi yang diambil untuk dijadikan sampel. Untuk jumlah sampel dihitung menggunakan rumus slovin. Jadi, Sampel yang akan diambil dalam penelitian ini 84 responden. Skala yang digunakan dalam penelitian ini adalah Skala Likert. 


\section{Definisi Operasional Variabel}

Dalam memperjelas definisi operasional variabel penelitian ini maka dibuat tabel yang menerangkan variabel, indikator dan parameter sebagai berikut:

\begin{tabular}{|c|c|c|}
\hline Variabel & Indikator & Parameter \\
\hline \multirow{6}{*}{$\begin{array}{l}\text { Iklim Komunikasi adalah } \\
\text { persepsi-persepsi yang } \\
\text { muncul dari pengalaman } \\
\text { pegawai dalam } \\
\text { berkomunikasi tentang } \\
\text { saling percaya, partisipasi } \\
\text { dalam pembuatan } \\
\text { keputusan, pemberian } \\
\text { dukungan serta } \\
\text { keterbukaan dan kerelaan } \\
\text { mendengarkan komunikasi } \\
\text { kebawah. }\end{array}$} & a. Kepercayaan; & $\begin{array}{l}\text { - Atasan percaya kepada } \\
\text { pegawainya. } \\
\text { - Pegawai percaya kepada } \\
\text { atasannya. }\end{array}$ \\
\hline & $\begin{array}{l}\text { b. Pembuatan } \\
\text { keputusan bersama; }\end{array}$ & $\begin{array}{l}\text { - Pegawai diberi kebebasan } \\
\text { berpendapat. } \\
\text { - Atasan menghargai } \\
\text { pendapat, ide dan saran } \\
\text { pegawai. }\end{array}$ \\
\hline & c. Kejujuran; & $\begin{array}{l}\text { - Suasana umum hubungan } \\
\text { diliputi kejujuran dan } \\
\text { keterusterangan. }\end{array}$ \\
\hline & $\begin{array}{l}\text { d. Keterbukaan dalam } \\
\text { komunikasi } \\
\text { kebawah; }\end{array}$ & $\begin{array}{l}\text { - Atasan memberi } \\
\text { informasi dan } \\
\text { mensosialisikan tentang } \\
\text { kebijakan kantor pada } \\
\text { pegawai. } \\
\text { - Pegawai mendapat } \\
\text { informasi berkaitan } \\
\text { tupoksi dalam kantor. }\end{array}$ \\
\hline & $\begin{array}{l}\text { e. Mendengarkan } \\
\text { dalam komunikasi } \\
\text { keatas; }\end{array}$ & $\begin{array}{l}\text { - Informasi dari pegawai } \\
\text { dipandang cukup penting } \\
\text { oleh atasan. } \\
\text { - Atasan mendengarkan } \\
\text { saran atau laporan } \\
\text { masalah yang diajukan } \\
\text { pegawai }\end{array}$ \\
\hline & $\begin{array}{l}\text { f. Perhatian pada } \\
\text { tujuan-tujuan } \\
\text { berkinerja tinggi }\end{array}$ & $\begin{array}{l}\text { - Instansi/lembaga } \\
\text { pemerintah } \\
\text { memperhatikan } \\
\text { kesejahteraan pegawai. } \\
\text { - } \text { Kantor memberikan } \\
\text { pelatihan pegawai }\end{array}$ \\
\hline
\end{tabular}




\begin{tabular}{|c|c|c|}
\hline \multirow{5}{*}{$\begin{array}{l}\text { Kinerja merupakan hasil } \\
\text { kerja atas suatu pekerjaan } \\
\text { selama periode tertentu } \\
\text { yang dihasilkan dari } \\
\text { seorang atau sekelompok } \\
\text { pegawai secara kualitas } \\
\text { dan kuantitas sesuai } \\
\text { dengan wewenang dan } \\
\text { tanggung jawab yang } \\
\text { diberikan kepadanya di } \\
\text { dalam suatu organisasi. }\end{array}$} & a. Kualitas kerja & $\begin{array}{l}\text { - Melakukan inovasi saat } \\
\text { bekerja sehingga } \\
\text { mendapatkan hasil lebih } \\
\text { optimal } \\
\text { - Hasil kerja hanya sedikit } \\
\text { mendapat kesalahan }\end{array}$ \\
\hline & b. Kuantitas kerja & $\begin{array}{l}\text { - Melakukan pekerjaanrutin } \\
\text { yang } \\
\text { diselesaikanberdasarkan } \\
\text { deadline yang sudah } \\
\text { ditentukaninstansi. } \\
\text { - Melakukan } \\
\text { tugastambahan } \\
\text { yangdiberikan secara baik }\end{array}$ \\
\hline & c. Ketepatan waktu & $\begin{array}{l}\text { - Menyelesaikan tugas } \\
\text { pekerjaan dengan baik dan } \\
\text { tepat waktu }\end{array}$ \\
\hline & d. Efektivitas biaya & $\begin{array}{l}\text { - Bekerjasemaksimal } \\
\text { mungkinwalaupun } \\
\text { kadang alatyang } \\
\text { digunakan untukbekerja } \\
\text { kurangmaksimal. } \\
\text { - Menggunakan } \\
\text { fasilitaskantor } \\
\text { sesuaikebutuhan } \\
\text { pekerjaan. }\end{array}$ \\
\hline & e. Pengawasan & $\begin{array}{l}\text { - Melaksanakan } \\
\text { tugaspekerjaan } \\
\text { tanpadiingatkan oleh } \\
\text { atasan } \\
\text { - Melaksanakantugas } \\
\text { pekerjaan } \\
\text { denganpengawasan } \\
\text { pimpinan } \\
\end{array}$ \\
\hline & f. Interpersonal impact & $\begin{array}{l}\text { - Dapat bekerja sama dalam } \\
\text { tim dengan baik sesuai } \\
\text { dengan timnya }\end{array}$ \\
\hline
\end{tabular}

Untuk menjawab rumusan masalah pertama maupun kedua sekaligus menjawab hipotesis iklim komunikasi dan kinerja dalam penelitian ini menggunakan rumus Chi Square Goodness Of Fit. Sedangkan untuk menjawab rumusan masalah ketiga mengenai pengaruhiklim komunikasi dengan kinerja digunakan statistik Regresi Linier Sederhana. 


\section{HASIL DAN PEMBAHASAN}

\section{Iklim komunikasi}

Tabel 1. Iklim Komunikasi Pegawai

\begin{tabular}{clcc}
\hline No. & Keterangan & F & $\mathbf{\%}$ \\
\hline 1. & Sangat Baik & 4 & 4,8 \\
2. & Cukup Baik & 47 & 56,0 \\
3. & Kurang Baik & 21 & 25,0 \\
4. & Tidak Baik & 12 & 14,3 \\
\hline & Jumlah & 84 & 100,0 \\
\hline
\end{tabular}

Sumber: Data primer diolah, 2018

Berdasarkan tabel 4.27.tersebut, ternyata kesimpulan disemua kategori iklim komunikasi pegawai di Kantor Kementerian Agama Kota Banjarmasin, yang termasuk kategori Cukup Baik sebanyak 47 orang (53,3\%), sedangkan kategori Kurang Baik 21 orang (25,0\%), serta kategori Tidak Baik 12 orang $(14,3)$ dan ada 4 orang $(4,8 \%)$ yang termasuk kategori Sangat Baik. Hal ini menunjukan bahwa iklim komunikasi pegawai di Kantor Kementerian Agama Kota Banjarmasin Cukup Baik.

\section{Kinerja Pergawai}

Tabel 2.Kinerja Pegawai

\begin{tabular}{clcc}
\hline No. & Keterangan & F & $\mathbf{\%}$ \\
\hline 1. & Sangat Baik & 4 & 4,8 \\
2. & Baik & 8 & 9,5 \\
3. & Cukup Baik & 10 & 11,9 \\
4. & Kurang Baik & 50 & 59,5 \\
5. & Tidak Baik & 12 & 14,3 \\
\hline & Jumlah & 84 & 100,0 \\
\hline
\end{tabular}

Sumber: Data primer diolah, 2018

Berdasarkan tabel 2.tersebut, ternyata kesimpulan disemua kategori kinerja pegawai di Kantor Kementerian Agama Kota Banjarmasin, yang termasuk dalam kategori Kurang Baik sebanyak 50 orang (59,5\%), sedangkan kategori Tidak Baik sebanyak 12 orang (14,3\%), kategori Cukup Baik 10 orang (11,9\%), serta kategori Baik sebanyak 8 orang $(9,5 \%)$, dan hanya ada 4 orang $(4,8 \%)$ yang termasuk kategori Sangat Baik. Hal ini menunjukan bahwa kinerja pegawai di Kantor Kementerian Agama Kota Banjarmasin Kurang Baik.

Jurnal Komunikasi Bisnis dan Manajemen

Vol.6 No.1 Januari 


\section{Pengaruh Iklim Komunikasi terhadap Kinerja}

Tabel 3. Pengaruh Iklim Komunikasi dengan Kinerja

\begin{tabular}{|c|c|c|c|c|c|}
\hline \multicolumn{6}{|c|}{ Coefficients $^{a}$} \\
\hline \multirow{2}{*}{\multicolumn{2}{|c|}{ Model }} & $\begin{array}{l}\text { Unstandard } \\
\text { ized } \\
\text { Coefficients }\end{array}$ & $\begin{array}{c}\text { Standardiz } \\
\text { ed } \\
\text { Coefficient } \\
\text { s }\end{array}$ & & \\
\hline & & Std. Error & Beta & $\mathrm{t}$ & Sig. \\
\hline 1 (Constant) & 44,997 & 3,190 & & $\begin{array}{r}14,10 \\
7\end{array}$ & ,000 \\
\hline $\begin{array}{l}\text { Iklim } \\
\text { Komunikasi }\end{array}$ &,- 117 & ,076 &,- 168 & $-1,543$ & , 127 \\
\hline
\end{tabular}

a. Dependent Variable: Kinerja

Pada tabel di atas, koefisien regresi -0,117 dan konstanta sebesar 44,997, sehingga diperoleh model regresi:

$\mathrm{Y}=44,997+-0,117 \mathrm{X}$

Persamaan tersebut menunjukkan bahwa setiap terjadi perubahan iklim komunikasi sebesar satu persen tidak serta merta akan diikuti dengan perubahan kinerja pegawai sebesar $-0,117 \%$. Secara umum nampak koefisien regresi tersebut bernilai negatif, sehingga dapat dikatakan bahwa arah pengaruh veriable $\mathrm{X}$ terhadap $\mathrm{Y}$ adalah negatif. Berdasarkan nilai signifikan dari tabel Coefficients diperoleh nilai signifikansi sebesar 0,127 > 0,05 sehingga dapat disimpulkan bahwa Hoyang menyatakan tidak terdapat hubunganantara iklim komunikasi dengan kinerja pegawai di Kantor Kementerian Agama Kota Banjarmasin diterima atau variabel Iklim Komunikasi $(\mathrm{X})$ tidak berpengaruh terhadap variabel Kinerja $(\mathrm{Y})$. Hasil analisis peneliti ini sama bertentangan dengan hasil penelitian yang dilakukan oleh Yazid Halim (2016), Ahmad Fauzi (2014), Apriyanto Achmad Wibowo (2013), Nurul Andriana (2012) dan Mar'atus Sholichah (2012) yang menyatakan bahwa iklim komunikasimemiliki pengaruh dengan kinerja. 


\section{KESIMPULAN}

Berdasarkan hasil analisis tentang hubungan iklim komunikasi dengankinerja pegawai di Kantor Kementerian Agama Kota Banjarmasin maka dapat disimpulkan sebagai berikut:

1) Iklim komunikasi pegawai di Kantor Kementerian Agama Kota Banjarmasin, yang termasuk kategori Cukup Baik yang termasuk kategori Cukup Baik sebanyak 47 orang $(53,3 \%)$, sedangkan kategori Kurang Baik 21 orang $(25,0 \%)$, serta kategori Tidak Baik 12 orang $(14,3)$ dan ada 4 orang $(4,8 \%)$ yang termasuk kategori Sangat Baik. Hal ini menunjukan bahwa iklim komunikasi pegawai di Kantor Kementerian Agama Kota Banjarmasin Cukup Baik.

2) Kinerja pegawai di Kantor Kementerian Agama Kota Banjarmasin, yang termasuk dalam kategori Kurang Baik sebanyak 50 orang (59,5\%), sedangkan kategori Tidak Baik sebanyak 12 orang (14,3\%), kategori Cukup Baik 10 orang (11,9\%), serta kategori Baik sebanyak 8 orang $(9,5 \%)$, dan hanya ada 4 orang $(4,8 \%)$ yang termasuk kategori Sangat Baik. Hal ini menunjukan bahwa kinerja pegawai di Kantor Kementerian Agama Kota Banjarmasin kurang baik.

3) Pengaruh antara iklim komunikasi terhadap kinerja pegawai menunjukkan bahwa setiap terjadi perubahan iklim komunikasi sebesar satu persen tidak serta merta akan diikuti dengan perubahan kinerja pegawai sebesar -0,117\%. Secara umum nampak koefisien regresi tersebut bernilai negatif, sehingga dapat dikatakan bahwa arah pengaruh veriable $\mathrm{X}$ terhadap $\mathrm{Y}$ adalah negatif. Berdasarkan nilai signifikan dari tabel Coefficients diperoleh nilai signifikansi sebesar 0,127 >0,05 sehingga dapat disimpulkan bahwa Hoyang menyatakan tidak terdapat hubungan antara iklim komunikasi dengan kinerja pegawai di Kantor Kementerian Agama Kota Banjarmasin diterima.

\section{SARAN}

Dari kesimpulan yang telah dikemukakan berdasarkan hasil analisisyang diperoleh maka ada beberapa saran-saran yang perlu dijadikanpertimbangan yaitu: 
1) Berdasarkan hasil analisis tingkat iklim komunikasi pegawai hanya padakategori Cukup Baik. Hal ini menandakan masih ada pegawai yang iklim komunikasinya rendah. Oleh karena itu hendaklah pegawai di Kantor Kementerian Agama Kota Banjarmasin terusmeningkatkan iklim komunikasinya.

2) Berdasarkan hasil analisis tingkat kinerja pegawai termasuk pada kategori Kurang Baik. Hal ini diharapkan bagi pegawai yangkinerjanya masih rendah dalam melaksanakan dan menyelesaikan pekerjaannya perlu ditingkatkan.Oleh karena itu, diharapkan di Kantor Kementerian Agama Kota Banjarmasin harus terus mengoptimalkan kinerja pegawai.

3) Walaupun tidak adanya pengaruh antara iklim komunikasi dengan kinerja pegawai,hendaknya semua pegawai di Kantor Kementerian Agama Kota Banjarmasin harus tetap memperbaiki iklim komunikasinya,agar tercapainya hasil kerja atau kinerja yang optimal.

\section{DAFTAR PUSTAKA}

\section{Buku}

AW, Suranto. 2005. Komunikasi Perkantoran. Yogyakarta: Media Wacana

Djamaluddin,Arief. 2008. Pengembangan Sumber DayaManusia dalam PersainganGlobal.Jakarta:Pengembangan Bisnis danManajemen Global

Handoko, T. Hani. 2001. Manajemen Personalia dan Sumber Daya Manusia.Yogyakarta: BPFE-YOGYAKARTA

Kriyantono, R. 2008. Teknik Praktis Riset Komunikasi. Jakarta: Kencana Prenada Media Grup 2006. Riset Komunikasi. Jakarta: Kencana Prenada Media Group

Liliweri, A. 2011.Komunikasi: Serba Ada Serba Makna. Jakarta: Kencana

Litwin, G. and P. Stringer. 1968. Climate and Motivation; An ExperimentalStudy. Boston: Harvard University Press

Muhammad, Arni. 2005. Komunikasi Organisasi. Jakarta: Bumi Akasara

Mahsun, M. 2006. Pengukuran Kinerja Pelayanan Publik. Yogyakarta: Pondok Pustaka Jurnal Komunikasi Bisnis dan Manajemen Vol.6 No.1 Januari 
Masmuh, A. 2010.Komunikasi Organisasi Dalam Perspektif Teori dan Praktik. Malang: UPT Universitas Muhammadiyah Malang

Mathis, Robert L. dan John H. Jackson. 2002. Manajemen Sumber Daya Manusia. Jakarta: Salemba Empat

Pace, R. Wayne.and Don, F. Faules. 2005. Komunikasi Organisasi: Strategi Meningkatkan Kinerja Perusahaan. Mulyana D, Kuswarno E, Gembirasari, penerjemaah. Mulyana D, editor. Bandung: PT. Remaja Rosdakarya

Robbins, Stephen P. 2006. Perilaku Organisasi. Jakarta: Kelompok Gramedia

Schuler, R dan Suzan E. Jackson. 1999. Manajemen sumber daya manusia menghadapi abad 21. Jakarta : Erlangga

Sinambela, Lijan P. 2016. Manajemen Sumber Daya Manusia; Membangun Tim Kerja yang Solid untuk Meningkatkan Kinerja.Jakarta: Bumi Aksara

Sopiah. 2008. Perilaku Organisasional. Yogyakarta: Andi Yogyakarta

Sugiyono. 2016. Metode Penelitian Kuantitatif, Kulitatif dan Kombinasi (Mixed Methods). Bandung: ALFABETA

Sukmalana, Soelaiman. 2007. Manajemen Kinerja : LangkahEfektif untuk Membangun,Mengendalikan, dan EvaluasiKinerja. Jakarta:PT. IntermediaPersonalia Utama

Sutrisno, Edi. 2009. Komunikasi Dalam Organisai. Jakarta: KENCANA

Widodo, Suparno E. 2015. Manajemen Pengembangan Sumber Daya Manusia. Yogyakarta

\section{Skripsi/Tesis}

Andriana, A. 2012.Pengaruh Iklim Komunikasi Organisasi Terhadap Kinerja Jurnalis TVRI. Skripsi.Universitas Sultan Ageng Tirtayasa

Halim, Y. 2016. Pengaruh Iklim Komunikasi dalam Organisasiterhadap Kinerja Karyawan di Rumah Sakit Umum Pusat (RSUP) Fatmawati.Skripsi.Konsentrasi JurnalistikUniversitas Islam Negeri Syarif HidayatullahJakarta

Haryanti E. 2005. Analisis Pengaruh Gaya Kepemimpinan dan Iklim Organisasi Terhadap Kepuasan Kerja dan Kinerja Pegawai Kantor Kecamatan Gayamsari Pemkot Semarang.Tesis. Program Pasca SarjanaMagister Manajemen Universitas Diponegoro

Jurnal Komunikasi Bisnis dan Manajemen Vol.6 No.1 Januari 
Sholichah, M. 2012. Pengaruh Iklim Komunikasi Organisasi terhadap Kinerja Pegawai (Survey pada Bagian Humas Pemerintah Provinsi DIY).Skripisi.Program Studi Ilmu KomunikasiUniversitas Islam Negeri Sunan KalijagaYogyakarta.

Wibowo, A. Achmad. 2013. Pengaruh Iklim Komunikasi Organisasi dan Budaya Kerja terhadap Kinerja Guru SMK Negeri 11 Semarang.Skripsi.Pendidikan EkonomiUniversitas Negeri Semarang

\section{Jurnal}

Fauzi, A. 2014.Pengaruh Iklim Komunikasi Organisasi Terhadap Kinerja Aparatur Di Pemerintahan Desa. Jurnal Sosiologi Pedesaan. Vol. 02 No. 03 Desember

Srivastav A. Kumar. 2006. Organizational Climate as a Dependent Variable, relationship with role stress, coping strategy and personal variables.Journal OfManagement Research. Vol.6 No.3

Vardi Y. 2001. The effects of organizational and ethical climate on misconduct at Work. Journal of Business Ethics.29, 325-337 